\title{
Social Justice and Converging Theories: Library Service for Those with Intellectual and Developmental Disability (IDD)
}

\author{
Matthew Conner \\ University of California, Davis \\ mconner@ucdavis.edu \\ Leah Plocharczyk \\ Florida Atlantic University, Jupiter \\ lplochar@fau.edu
}

\begin{abstract}
While libraries have sought to advance diversity in their services, they have yet to engage a specific population which tests the limits of the profession's capabilities and the scope of its mission. Those with Intellectual and Developmental Disability (IDD) combine the categories of learning and physical disabilities and demand the highest level of support. But the impediments to reading imposed by their cognitive condition make it difficult for them to access the library's materials. Beset by funding shortages and systemic change, what are libraries to do? This study examines how convergent trends in educational theory and practice as well as grassroots initiatives have created new possibilities for library services to this population. The study reviews these trends as well as a case study to suggest that libraries have much of what they need in their traditional programming and training when combined with a deeper understanding of the dynamics of social justice.
\end{abstract}

\section{Introduction}

By any estimate, librarianship, as a profession, is undergoing a period of radical change as seen by unmistakable historical markers. In particular, the rise of the internet and the so-called Information Revolution, a development that has been compared to the invention of the printing press, has had a particularly strong impact on libraries whose work has been bound up with texts since antiquity. In addition to changes in the nature of texts, libraries also grapple with changes in the patrons who read these texts. More specifically, libraries reflect the increasing social awareness of the $20^{\text {th }}$ century in their recognition of diversity. Emphasizing a service ethic, at least since the rise of modern librarianship in America in the $19^{\text {th }}$ century, libraries have increasingly sought to provide the widest array of reading materials to the widest array of patrons. Amidst this complex and changing landscape, this study suggests that cultural theory (and an enlarged global perspective that it implies) provides a means to identify a major challenge to libraries in their mission and also provides a solution to it. Specifically, those with intellectual and developmental disability (IDD), a long neglected population, poses practical challenges to library service with their impediments to learning to read-questions of funding, procedure, policy, and their consequences for which the best-intentioned theory has no answer. But convergent theoretical developments in educational theory, multiculturalism, technology, and social justice suggest a surprising solution, one hiding in plain sight in skills that librarians already use and in a reinterpretation of their mission. 


\section{Professional Dilemma}

Those with IDD are defined as individuals with IQ's below 75 and associated difficulties in communication, socializing and self-care. They span a number of other categories of disability such as learning and physical disability (American Association of Intellectual and Developmental Disabilities, 2019). Physical disability describes individuals with limited mobility and compromised physical functioning which includes developmental disabilities (Center for Disease Control and Prevention, 2018). Learning disabilities are neurologically-based conditions that interfere with processing and comprehension (Learning Disabilities Association of America, 2019; National Institute for Neurological Disorders and Stroke, 2019). Those with IDD can be understood (like a Venn diagram) as an intersection of both categories, learning and physical disabilities. Moreover, a category that is nominally one (e.g. learning disability) can function as the other (physical disability). For example, an inability to read and understand limits an individual's access to transportation. Conversely, a physical impairment, such as blindness, interferes with the ability to read and learn. As a composite of disabilities, the category of IDD makes the most urgent demands for attention on anyone seeking to advance diversity and equality, such as those in the library profession. Librarians, however, have compelling reasons to be deliberate in addressing this group. In a time of scarce funding for all of higher education, there is barely enough money to sustain the library's traditional functions of collection, reference, and instruction while trying to keep up with rapidly changing technologies (Mathuews, 2016, p. 7). There is little left over to pursue every possible initiative, let alone a new venture that is poorly understood and for which librarians have no training. The library profession is thus caught on the horns of a dilemma: Either commit to an ill-defined and unfeasible new mission to serve persons with IDD or admit that diversity has limits after all and that the library does not serve everybody.

Not only is service to this population an ethical crisis for libraries, but it is significant for those with ID as well. (We will use the shortened form of the acronym for convenience and because those in our case study presented ID with few other developmental disabilities in evidence. The subjects of the study constitute a subset of IDD.) Those with ID have been integrated into public education due to a sequence of legislation that goes back to the 1960s (Ashbaker, 2011), but few means have been found to accommodate them afterwards. Upon graduating from high school, the students lack most of the opportunities for employment, education, recreation, and socializing available to their peers. Often they languish in their parents' homes, losing the skills that they gained in high school (National Organization on Disability, 1998; Standards Committee Subcommittee to Develop Guidelines for Library Services for People with Mental Retardation, 1999). As one of the few social institutions open to everyone, libraries are a critical resource. But without libraries providing effective service, even this resource is denied. Improvement in library service is important both for the professional identity and mission of libraries and the well-being of those with ID.

Libraries have attempted to serve those with ID as part of their more general efforts to support disability. These attempts have been grouped into three broad categories: outreach, specialized collection centers, and mainstreaming (Wells, 1995, p. 211). The first involves advertising to 
invite those with ID into the library. This could be targeted at specific institutions or programs. The second category addresses what those with ID do once they arrive at the library. Recognizing that most, if not all, of the library's collection would not be relevant, specialized collection attempts to gather materials that would be useful. Just what that might be awaits discussion in the scholarly literature. In addition to materials for learning and enjoyment, such centers also stock information on self-advocacy. This can be useful to both those with ID as well as their caretakers. The third option is something of a reaction to the second. Rather than isolating useful materials in one place, this initiative seeks to make the entire library accessible to everybody. This effort would include training for all staff, an overhaul of the physical facility, and major changes to the arrangement and content of the collection. While most desirable from the viewpoint of integration, the last option is the most expensive and least practical. None of these programs have been successful, showing little participation and dwindling rapidly after grant funding has run out (LaDuke, 1994; Mulliken \& Atkins, 2009).

\section{Grassroots Initiatives}

A new initiative has shown great promise in the form of book clubs for those with ID, however. They are the creation of Dr. Tom Fish, the Director of the Nisonger Center for Disability at Ohio State University. While puzzling over the problem of supporting adults with ID after high school, he came up with an audacious plan. Why not meet the needs of the group directly by having informal book clubs meet in public spaces? This would provide both education and socialization at the same time (Fish \& Graff, 2006). Fish was partly inspired by one of the students of his program who would follow a morning routine of going to a lounge and opening a newspaper, although he could not read. This incident spoke to Fish about the desire for inclusion through literacy. It also raised the question of how the idea would work if the participants could not read. But Fish thought, "What if they could?" The program also avoided this problem by blending reading and socialization together. Rather than applying a pedagogy, the system allowed the participants to use one element against another. When reading got too difficult, they could socialize. When looking for something to discuss, the participants could use the reading. The format reproduced a natural form of learning that everyone experiences before the start of formal education (see our discussion below on "preliteracy"). It seemed worth a try.

The idea succeeded beyond all expectations. Originally planned for the local community around the university, the idea took off under its own impulse through social media. Here, it was aided by its lack of centralized control. Participants needed only a book and a public space. Upon seeing how it worked, others were moved to imitate. Started in 2002, the idea has spread across the United States with 230 participating chapters and is rapidly forming new chapters overseas (Fish, Brooks, \& Allbee, 2018). The movement is now organized as the Next Chapter Book Club (NCBC) run by Fish, but it maintains a light touch. NCBC has few requirements that are limited to preserving the key features of the original vision. Among the most important is restricting the group size to eight to ensure the ease and participation of the members. Otherwise, NCBC plays 
a largely supporting role, maintaining lists of reading suggestions and providing simple training to facilitators. ${ }^{1}$

\section{Educational Theory}

It is worth examining the reasons for the effectiveness of this successful phenomenon at addressing such a difficult task where many have failed. To do this, we need to go back to the field of education from which Fish seemingly diverged with his unconventional idea. We also need to go back in time and across cultures to a Russian educator in the early $20^{\text {th }}$ century named Lev Vygotsky. Vygotsky's thought, in turn, can only be appreciated fully within the context of emerging Marxist thought. Coming amidst the scientific advances of the late $19^{\text {th }}$ century, Marxism introduced dialectical materialism to the study of societies (Satgar \& Williams, 2017). This view held that social dynamics could be understood in material terms. Rather than the mysticism of earlier eras, such as the religious belief in the divine right of kings or "self-evident" truths of a rational Creator (cited by the Founders of the American Republic), Marxism imagined that social structure was formed from wholly material forces. These motive forces, driven by economics, shaped class warfare in which the wealthy oppressed and exploited the mass of laborers to retain privilege. This economic structure was the "base," which founded a "superstructure" of belief systems whose ultimate goal was to maintain the social hierarchy. Society and all of its human aspirations was recast as a wholly material phenomenon.

Russia was a particularly visible expression of Marxism, whose population revolted against a vast authoritarian tradition to create a Communist state, one of the most powerful and influential nations of the $20^{\text {th }}$ century. With its creation, Russian intellectuals sought to adapt Marxism to establish an entirely new culture. They gave particular attention to the "superstructure" of belief systems and academic disciplines, which were their field of activity. Vygotsky (1978) took on the task of relating Marxism to education and psychology (Cole \& Scribner, 1978, p. 7). To do this, he made use of what has since become Marxist literary theory and its concept of the sign. As part of its global revision of human history and culture, Marxists took particular interest in literature and the arts. The West, against which Marxism reacted, had a long history of imitating classical culture in its reverence for these fields of activity. The ancient world had associated the arts with the divine, embodying artistic inspiration in the form of nine minor goddesses, known as Muses, and these remained common poetic symbols in English literature into the $19^{\text {th }}$ century. This would not do for the Marxists and their materialist vision. They reformulated artistic symbolism as signs, which they defined as the wholly material expressions of ideology, belief systems anchored in some economic or other material process. Vygotsky adapted both signs and dialectical materialism to the fields of education and psychology. Rather than conflict between social classes, he imagined a dialectic between the individual consciousness and external reality coded as signs (Vygotsky, 1978, pp. 46, 60). The interaction between these two he modeled as the fundamental process of education. Signs, in the form of symbols and the concepts they signify, impact and reshape the individual consciousness, which, in return, perceives subsequent signs in a different way. While the process assumes a general upward trajectory, it is as difficult

\footnotetext{
${ }^{1}$ The same ideas were discovered independently, at about the same time, by Nancy Comer, the mother of a son with ID, and systematized in the Books for Dessert program at the Port Washington Branch of the New York Public Library system (Port Washington Public Library, 2017).

Journal of Contemporary Issues in Education, 2020, 15(1), pp. 81-94. (c) Author(s), Creative Commons Attribution 4.0 (CC BY 4.0) licence http://ejournals.library.ualberta.ca/index.php/JCIE doi 10.20355/jcie29393
} 
and unpredictable as one might imagine from the analogy of class warfare and from experience with the classroom environment. Through difficulty or irrelevance, signs may have no impact on a student at all. Where there is a connection, student responses may take a wide variety of forms including interest, admiration, comprehension, disagreement, disgust or puzzlement. It is only when the signs are appropriately matched to consciousness that learning takes place. The parameters of such a match are the definition of Vygotsky's Zone of Proximal Development (ZPD) which has become a seminal concept of education theory (Del Rio \& Alvarez, 2007, p. 277). This principle has had enormous impact on testing and curriculum development, but it can be fully appreciated only through its often overlooked theoretical origins.

\section{Context-Based Learning}

Two principles of the ZPD are especially relevant to our discussion of the Next Chapter Book Club. One is the notion of context-based learning (a ubiquitous concept in educational theory and pedagogy that derives from many sources). Rather than regarding meaning as fixed, this viewpoint considers it as dependent on its context (Alfassi, Weiss, \& Lifshitz, 2009; Harris, Golinkoff, \& Hirsh-Pasek, 2011). The nature of the context has proven highly flexible. It can mean a surrounding narrative, the way a text is performed, the physical environment of learning, one's learning community, and more. From an educational perspective, context can be manipulated to enhance the learning process, and the ZPD has proven very useful here. A structure of signification with all of the above elements can be designed around a student.

The second application of the ZPD is more specific and refers to its use at an especially critical moment in the learning process: when an individual learns to read. The dynamics of this crucial step are not well-understood as evidenced by the diversity of approaches to it. An earlier approach to literacy was based on a subdivision into components. For disadvantaged learners, this process was taken to an extreme. Words were broken down to syllables, letters, pronunciation, and appearance, and learned through definitions. Once the elements were sufficiently simplified and mastered through repetitive drill, they would be reassembled into the process of reading (Katims, 2001, p. 10). It is worth noting that this approach, with its division into parts, was the very antithesis of context-based learning. So, when this method failed to produce results, it is not surprising that the paradigm shifted completely to context-based learning. Vygotsky (1978) formulated a specific type of ZPD for this situation which he called "pre-literacy" (p. 110), a term that remains in use. This concept proposes that the initiation of reading is not a systematic process. Rather it proceeds in a natural and organic way by the immersion of the learner in a bath of language-rich activities. These include listening to advanced conversation, being read to, and viewing film or drama. The type of presentation is less important than the variety of presentation. And the level of difficulty is not crucial as long as it is not excessive or specialized and unfamiliar. The learning mind has some way of processing all of this. If the person does not begin reading spontaneously, such preparation appears to help get them to that point (Strang \& Piasta, 2016, p. 1338; Saint-Laurent, Giasson \& Couture, 1998, p. 267; Chang \& Monaghan, 2019, p. 236).

Both the ZPD, generally, and pre-literacy, specifically, offer highly suggestive explanations for the unexpected success of NCBC. In particular, they explain the distinctive connection between reading and socialization. These two are often thought of separately with the library as a 
stereotyped location where people read silently in their own worlds and any talking is quickly suppressed. Socialization was originally added by NCBC to supplement reading and to address another need of those with ID for conversation and company. But Vygotsky's work on the ZPD indicates how this apparent deviation might play a crucial role in the learning process as well. Any language-rich activity increases the learning process, so talking alone is educational for the students. Taking with others is thus much more conducive to literacy development than sitting at home alone. And talking is just the first in a wide range of socialization possibilities in the NCBC format.

\section{Universal Design for Learning (UDL)}

Another related theory of learning is relevant as well, coming out of the same broad movement of context-based learning. It aspires to be comprehensive, as suggested by its name, Universal Design for Learning (UDL). The theory, residing in disability studies, began in the field of architecture with the concept of Universal Design (Meyer, Rose, \& Gordon, 2014, p. 86). Rather than creating separate facilities for those with physical disabilities, the movement reversed assumptions by seeking a design that would work for everyone. Not only did such design solve practical problems, but it also achieved the higher goal of integrating those with disabilities into society rather than sequestering them. The paradigmatic example of Universal Design is the curb cut, a ramp cut into sidewalks that had proved difficult to negotiate for those with physical disabilities. In addition to supporting those with wheelchairs, crutches, and scooters, the curb-cut turned out to be preferred by the typical population as a matter of convenience. So successful was the curb cut that efforts began to generalize it to other situations. One of the more ambitious was to abstract it to a learning method. Just as physical barriers, such as curbs and stairs, could be removed, perhaps barriers to education could be removed as well in the quest for equality. One example of this is captions to video. Developed originally as a means to assist those hard of hearing, they have been found useful for the typical population for viewing in a crowded area and for multitasking. The captions serve as a curb cut of the senses, facilitating communication among those with different capabilities and situations.

The abstraction of Universal Design has culminated in the movement of UDL. In essence, UDL holds that learning depends much more on one's learning style than on native ability (Grigal, Hart, \& Paiewonsky, 2010, p. 236). Everyone has characteristic ways of learning that have been divided into three categories. The affective category identifies the motive for learning. The representational category identifies the form of knowledge preferred: written, visual, or spoken. The strategic principle describes how the individual organizes their learning process such as for immediate or delayed gratification (Meyer et al., 2014, p. 87-89). Since any random selection of students will have an assortment of learning styles, the instructor needs to devise ways to incorporate them all. A prominent technique is to have students learn from each other (Meyer et al., 2014, p. 149). This openness to all learning styles is the instructional analogue of the curb cut, which allows all to participate in a common format. Assessment is ongoing with the movement of UDL that continues to evolve. Yet, a systematic study of research identifies positive outcomes and future promise (Ok, Rao, Bryant, \& McDougall, 2017, p. 116).

Considering the different abilities of those with ID, from the typical population and from each other, UDL has a natural compatibility to the NCBC environment, and, in turn, NCBC could serve as a means of studying UDL. 
With these subtle but powerful correlations with educational theory, NCBC book clubs would appear to have much to offer public libraries, a social institution devoted to reading, but this connection was not immediate. When libraries were first proposed as NCBC sites, they were denied, and the reason given was the "shush" sign of two fingers to the lips (Fish \& Rabidoux, 2009 , p. 82). Since NCBC emphasizes communication, the perception of rigidly enforced silence disqualified it; libraries were hurt by popular stereotypes. However, both libraries and outside perceptions of them have evolved, and NCBC now has chapters in 60 public libraries throughout the United States (Next Chapter Book Club, 2018). However, there is another notable barrier to the use of NCBC in libraries. A significant branch of the library profession is academic libraries which serve university and college campuses. These libraries serve those who continue their education after high school, the very age group where those with ID are cut loose from society. Since those with ID do not traditionally attend college, academic libraries are largely uninvolved with them. Granted, those with ID can use public libraries and the NCBC clubs there. However, they lose the considerable resources of academic libraries in their area. And the college communities lose the diversity to be gained from those with ID.

\section{Post-Secondary Education}

Yet, this situation may be changing as well. The organization ThinkCollege! has both promoted and tracked the development of Post-Secondary Education (PSE) programs for those with ID (Grigal, Hart, \& Paiewonsky, 2010). Their goal is to allow the students to develop communication and social skills, gain vocational or "life" skills, and generally have the experience of a college education. A search of their database yields 165 four-year college programs across the country reporting a PSE program (ThinkCollege!, 2018). Details of this study and its results are available in Libraries and Reading: Intellectual Disability and the Extent of Library Diversity (Conner \& Plocharczyk, 2020). Suffice it to say that in the descriptions submitted by the 165 programs, not a single one mentioned the participation of their campus library. In a way, this does not surprise. Academic libraries have traditionally catered to higher education, not elementary instruction of the kind traditionally associated with those with ID. On the other hand, the results show that academic libraries are falling behind other campus units, no better prepared, who have found ways to support those with ID. The presence of these students on campus in PSE programs gives academic libraries a better chance to support them than if these students were to reach out into community libraries on their own. Similar programs have been reported in the UK and Australia (Moni, Jobling, \& Baffour, 2018). These developments have positioned NCBC as a promising tool for libraries, both public and academic.

\section{Assessment}

The next question is to examine how NCBC programs have fared in both categories of libraries and how one assesses their accomplishments. The authors have identified 60 public libraries in North America with NCBC book clubs and have formed the first NCBC book club at the library of Florida Atlantic University (FAU) at its Jupiter campus. It is the first NCBC club at an academic library that we are aware of and has operated for four years at this writing. The academic library club recruits its members from its university's PSE program. Thirty of the public library clubs were surveyed, and the results were compared with a detailed assessment of the academic library club. This information is available in Libraries and Reading: Intellectual 
Disability and the Extent of Library Diversity (Conner \& Plocharczyk, 2020). For the moment, we will present very broad conclusions. The first and most fundamental is that the book clubs in libraries are viable based on attendance records. Across all the libraries surveyed, the 30 public and one academic, attendance was between 60 to $80 \%$ of the NCBC limit of eight members. The clubs were also sustainable in two respects. First, clubes sustained themselves over a period of time. The academic library club is now in its fourth year, and some of the public library clubs have persisted for as many as 6 years. The second point is that none of the clubs required significant outside support. They mostly used the time of the librarians and a meeting space, although some were able to use their library's collection budget or find support through library associations. In the case of the academic library club, the cost of buying books and snacks for the students mounted up over time. Over the course of three years, it amounted to approximately $\$ 2000$. Currently, efforts are underway to find supplementary funding through collaboration with campus units and community businesses. Such as they are, however, these expenses remain a small part of a library's budget and not on the same order as expenses for training staff or arranging elaborate programming.

The actual activities of the book clubs and their assessment are just beginning to be examined. For now, we can say that most of the clubs have followed the original example of NCBC in mixing reading with informal discussion and socializing. The academic library club is unique in pioneering the use of educational games. Since there is no source of games for those with ID, the academic library facilitators developed their own by modifying conventional games or creating new ones. Pictionary, Charades, and quiz question games were highly popular and engaged the students as much as the readings. They were adapted as much as possible to the subject matter of the books. For example, clues for Pictionary and Charades were chosen thematically, and students could express them through drawing, acting, and verbal cues. The facilitators were startled at the enthusiasm of the students who never tired of these activities. A full list of the games and their success would require a separate discussion.

\section{Social Justice Librarianship}

As a final point about the book clubs, we might consider how they fit into the larger movement undertaken by the library profession to support diversity. The profession has appropriated the term social justice to form "library social justice," a prominent topic in the research literature. But what does it mean? Social service has been a defining concept of modern libraries since their inception. What about current practice merits a different title? While social justice is a somewhat broad, amorphous effort to promote equality, it can be linked to Civil Rights, the last formal struggle for equality in America. With much turmoil and a certain amount of violence during the 1960s, the Civil Rights movement gained equal legal rights for women and racial minorities. But while it achieved its goals, injustice persisted. In part, the same work continues. Where the original Civil Rights protesters fought for the rights of African-Americans and women, activists have expanded the struggle for legal rights to new groups such as transgender and LGBTQ+. But the struggle now has taken on a qualitatively different character. While African-Americans, for instance, are no longer denied voting rights (at least explicitly) or relegated to the back of the bus, they suffer racial profiling by police, racial stereotypes, hate speech, and discrimination through a disparity in wealth that is increasing with time. New social boundaries have appeared 
in the form of barriers to education and information. These new oppressions are as destructive as the old and more insidious.

Cultural Studies defines oppression as ways of representing that consolidate power for the privileged by embedding hidden assumptions and practices that lie outside our conscious awareness (Mathuews, 2016, p. 7). Familiar examples would be the r-word and other derogatory terms formerly used to classify those with ID by their cognitive limitations. Such classifications preclude respect and social interaction from the start, and they make it easy to ignore or marginalize these individuals. The same pernicious attitudes persist in subtler form. To refer to the majority of the population as "normal" is to implicitly define those with ID as "abnormal" or Other. Even the classification "disabled" has a demeaning effect in reducing an individual to one feature. This is the rationale for the current convention of "person first" terminology, where one refers to the individual before their condition as in "those with ID" (Jensen et al., 2013). Ideology is so subtle that a continuing effort at self-awareness is required to keep old attitudes and prejudices from reappearing. This vigilance is now considered the front line of activism-as opposed to the earlier marching and civil disobedience.

Applying Cultural Studies to disabilities has led to the sub-field of "critical disability theory." Some of its major themes are exemplified by Erevalles (2014), who explores the positionality of disadvantaged identities and undertakes a "relational analysis to engage the material of disability at the intersections of race, class, gender, nation, and sexual identity within specific historical contexts and discuss the complicated impasses that continue to plague disability studies at these intersections" (Erevalles, 2014, p. 1). Davy (2015) analyzes the concept of "self-determination." She finds that this overt goal of diversity is, in fact, a means of oppression, promoting values that favor the typical population. A worthier goal, in her opinion, is to recognize "autonomy as a feature of persons that is manifested only through relations of support, advocacy, and enablement" (Davy, 2015, p. 132). While these intricate studies add to the body of theory, they also reveal a unique aspect of librarianship as an academic discipline. Though participating in theory, librarianship is also deeply committed to service and concrete results - a standard against which the pieces by Erevalles and Davy fall conspicuously short. How will their proposals address the pain of those with ID in being shut out of jobs, independence, and socialization? We can test the objections to self-determination against what is probably the single greatest service achievement of modern librarianship in the United States: the literacy instruction given to multitudes of immigrants at the turn of the $20^{\text {th }}$ century (Ditzion, 1947, p. 137). This massive educational effort is credited with assisting millions of individuals and enhancing the diversity of the nation. Yet, presumably the apparent "self-determination" gained through language skills would constitute a liability according to critical disability theory by reinforcing oppressive values. An alternative in which illiterate immigrants would have accepted their dependence is hard to visualize, much less see as an improvement.

This is not to dismiss theory. Rather it is to suggest a compromise that turns theory to more practical applications. We propose to do this by going back beyond critical disability theory to its roots in Cultural Studies which, in turn, is based on the Marxism that inspired Vygotsky.

\section{Strategies of Representation}


The concept of a sign is crucial to any understanding and application of Cultural Studies. A simple definition of a sign, which derives from the work of Charles Saunders Peirce, is "something which can stand for something else" (Dictionary, n.d.). It is the fundamental unit of representation. Most obviously, signs include language, but also graphics, colors, movements, clothing, shapes - basically, anything that can be imbued with meaning by an observer. This broad definition leads to many ways of construing signs and interactions between them. Vygotsky's work on the ZPD, with its relation between consciousness and signs, illustrates the complexity of these interactions. If signs are an instrument of oppression as described above, they can also be used as a form of resistance as well, and some methods of doing this have been recognized. One is "deconstruction," in which close analysis reveals signs to have arbitrary and contradictory meanings rooted in a fundamental indeterminacy in language (Castle, 2013). As an example, take the process of "Othering" or excluding someone as different and inferior, a form of representational oppression (Treanor, 2006, p. 2). This can be expressed as racism, sexism, classism, moral self-righteousness, and other means by which people differentiate themselves. Applications of deconstruction analyze a representation to show how distinctions are arbitrary and how the Other is actually indistinguishable from the "self" or agent of exclusion. Deconstruction can take place at an individual word level—witness Davy's analysis of "selfdetermination," where a seeming benefit acts as a type of oppression. Even Erevalles' "positionality" is based on the kind of linguistic relativism portrayed by deconstruction. Deconstruction can also lead to historical analyses of major social movements. From these we get evidence that Othering is not based on a genuine sense of superiority but rather on a hidden anxiety and belief that the Other is actually superior. Examples include Richard Slotkin's argument that American frontier myths denigrating Native Americans are rooted in the anxiety and guilt white settlers feel about stealing their heritage (Slotkin, 2000). In a similar vein, Eric Lott, in his study of blackface minstrelsy, argues that the driving force behind this overtly racist portrayal of black Americans was a hidden envy in the white audience, which covertly sought to experience black identity (Lott, 2013). More prosaically, we have religious figures who condemn homosexuality while they themselves while actively practicing it themselves (Manning \& Stern, 2016; Philips, 2019). All offer examples of how oppressive representation can be deconstructed to show its arbitrariness.

Another way to resist representational oppression is through the practice of "reappropriation." Appropriation is borrowing another person's culture or identity in order to exploit it, and reappropriation is the process of taking that identity back. This can be done by those who have been subject to exploitative representation adopting an offensive term to defuse its power (Pierce, 2001, p. 50). Consider "Yankee Doodle Dandy," originally a British term of derision for American revolutionaries, which became a symbol of American pride. Similarly the n-word, the worst of racist insults, is sometimes adopted by African-Americans as a casual form of reference to themselves (Rahman, 2012). Finally, the term "queer" originally used to denigrate the gay community has been reinvented as a label of pride and even a verb for resistance. To "queer" something is to change it, often in a way that advances the condition of gay individuals: "The following writers and artists are those whose work queers and troubles the constructs of gender, whether through performance, or the performative nature of the work itself' (Foreman, 2015, paragraph 5). The institutionalization of Queer Studies at universities is this same movement writ 
large, taking a former term of denigration as a term of pride. Like deconstruction, reappropriation is another strategy for resisting representational injustice.

Vygotsky, in addition to his accomplishments in education, can now be understood to add to this machinery of social justice with his uncannily prescient work. As part of his research in education, he studied disability, and unlike his contemporaries, he argued that those with disability could be educated. He articulated his method in the language of signs. Those with disability, he maintained, did not lack the capability to learn. Rather they were unable to process the same sign systems as the rest of the population. The solution was to find new pathways of signs that would lead them to the same goals (Kozulin \& Gindis, 2007, p. 345). Vygotsky's signs have been interpreted as assistive technology for those with disability. This technology is clearly engaged in forms of representation - audial, tangible (Braille), and graphic. And, in keeping with the broad concept of signs, assistive technology continues to grow in new forms. Originally designed for those with learning disabilities that affected only the transmission of information (e.g. blindness, deafness, dyslexia), it has been turned to with increasing success to those with ID, who have difficulty processing information according to expected courses of action (Irwin, 1995, p. 40).

Vygotsky's work can be applied to other types of representation as well. There is no better example than the library book clubs we have discussed. Various forms of reading pedagogy such as "echo reading" or dramatic readings represent new kinds of signification of texts. The mingled socialization and reading of NCBC clubs are examples of Vygotsky's preliteracy, and preliteracy illustrates how the entire learning environment, in addition to written texts, functions as a sign system for learning of great effectiveness. The games pioneered by the FAU club reveal another dimension of creative signification in the service of learning. Students who struggle with texts reveal often surprising levels of comprehension and creativity in their favorite games of Charades, Pictionary, and most forms of quiz games. These literacy-rich activities represent Vygotsky's alternative sign system by which students arrive at meaning through alternate routes. In doing so, they not only improve their reading and social skills, but also reverse the social expectations that work against them, starting with the hard names with which they have been abused for so long. Those with ID and their advocates need not engage in deconstruction and "high theory." The library book clubs we have discussed are just one means by which signs may be redefined to support those with ID towards their goal of community integration.

\section{Conclusion}

The issue of library service to those with ID reveals a significant social problem in terms of its emotional, physical, economic cost on those with ID, their caregivers, and any society that aspires to diversity. But this issue also reveals a significant convergence of theoretical trends and social movements that can potentially redress the problem. Legislation has done much for those with ID in integrating them into the public education system, but this achievement has created a lacuna of neglect for high school graduates who have no further avenues for education, socializing and self-development. Libraries, with their history of educational service, are critically positioned to address this need, but the means have been lacking. Previous forms of outreach and support have not sustained themselves. But new approaches have appeared from grassroots efforts. NCBC has remixed (resignified) older themes, audaciously pairing those with 
ID and books in the traditional format of the book club. Started in an informal and local setting, the movement has spread under its own impulse through social media throughout the United States and internationally. Its success appears to be underpinned by developments in general and special education that include Vygotsky's ZPD, group and context-based learning, and UDL. PSE, developed among university education departments, has also succeeded in establishing a foothold for those with ID with 165 four-year programs and 95 two-year programs in colleges in the United States. By incorporating NCBC programs into both public and academic libraries, librarians can not only provide a vital service to a population but also participate in the redefinition of assumptions and signs systems to bring about social justice.

\section{References}

Alfassi, M., Weiss, I., \& Lifshitz. (2009). The efficacy of reciprocal teaching in fostering the reading literacy of students with intellectual disabilities. European Journal of Special Needs Education, 24(3), 2291-2305. http://dx.doi.org/10.1080/08856250903016854

American Association of Intellectual and Developmental Disabilities. (2019). Intellectual disability. Retrieved from https://aaidd.org/intellectual-disability/definition

Ashbaker, B. Y. (2011). History of legal and legislative acts concerned with special education. In A. F. Rotatori, F. E. Obiakor, \& J. P. Bakken (Eds.), History of special education (Vol. 21, pp. 21-45). Emerald. http://dx.doi.org/10.1108/S0270-4013(2011)0000021005

Castle, G. (2013). Deconstruction. In G. Castle (Ed.), The literary theory handbook. Hoboken, NJ: John Wiley. Retrieved from https://ebookcentral.proquest.com/lib/ucdavis/detail.action?docID=1204089

Center for Disease Control and Prevention. (2018). Developmental disabilities. Retrieved from https://www.cdc.gov/ncbddd/developmentaldisabilities/facts.html

Chang, Y., \& Monaghan, P. (2019) Quantity and diversity of preliteracy language exposure both affect literacy development: evidence from a computational model of reading. Scientific Studies of Reading 23(3), 235-253.

Cole, M., \& Scribner, S. (1978). Introduction. In M. Cole, V. John-Steiner, S. Scribner, \& E. Souberman (Eds.), Mind in Society: The Development of Higher Psychological Processes (pp. 1-14). Harvard University Press.

Conner, M. \& Plocharczyk, P. (2020). Libraries and Reading: Intellectual Disability and the Extent of Library Diversity. Emerald Publishing.

Davy, L. (2015). Philosophical inclusive design: intellectual disability and the limits of individual autonomy in moral and political theory. Hypatia, 30(1), 132-148. Retrieved May 1, 2020 from onlinelibrary.wiley.com/doi/pdfdirect/101111/hypa.12119

Del Rio, P., \& Alvarez, A. (2007). Inside and outside the zone of proximal development: An ecofunctional reading of Vygotsky. In H. Daniels, M. Cole, \& J. V. Wertsch (Eds.), The Cambridge Companion to Vygotsky (pp. 276-304). Cambridge University Press. http://dx.doi.org/10.1017/CCOL0521831040.012

Dictionary.com. (n.d.). Symbol. Retrieved May 7, 2020 from dictionary.com/browse/symbol.

Ditzion, S. (1947). Arsenals of a democratic culture: A social history of the American public library movement in the New England and the Middle States from 1850 to 1900. American Library Association. 
Erevelles, N. (2014). Thinking with disability studies. Disability Studies Quarterly, 34(2).

Fish, T., \& Graff, V. (2006). Next Chapter Book Club: What a novel idea. Exceptional Parent, $36(11), 46-48$.

Fish, T., \& Rabidoux, P. (2009). Next Chapter Book Club: A model community literacy program for people with intellectual disabilities. Woodbine House.

Fish, T., Brooks, P. \& Albee, M. (2018). Literacy and community-building for adults with intellectual disabilities. Retrieved from https://www.webjunction.org/events/webjunction/next-chapter-book-club-webinar.html

Foreman, A. (2015). Queer as verb: 7 trans and non-binary artists doing the work. The Offing. Retrieved from https://theoffingmag.com/enumerate/queer-as-verb-7-trans-non-binaryartists-doing-the-work/

Grigal, M., \& Hart, D. (2010). Critical components for planning and implementing dual enrollment and other postsecondary education experiences. In M. Grigal \& D. Hart (Eds.), ThinkCollege!: Postsecondary Education Options for Students with Intellectual Disabilities (pp. 229-258). Paul H. Brookes.

Grigal, M., Hart, D., \& Paiewonsky, M. (2010). Postsecondary education: The next frontier for individuals with intellectual disabilities. In M. Grigal \& D. Hart (Eds.), Think College!: Postsecondary education options for students with intellectual disabilities (pp. 1-28). Paul H. Brooke.

Harris, J., Golinkoff, R. M., \& Hirsh-Pasek, K. (2011). Lessons from the crib for the classroom: How children really learn vocabulary. In S. B. Neuman \& D. K. Dickinson (Eds.), Handbook of Early Literacy Research (Vol. 3, pp. 49-65). The Guilford Press.

Irwin, M. (1995). The issues. In L. L. Walling \& M. Irwin (Eds.), Information services for people with developmental disabilities. Greenwood Press.

Jensen, M. E., Pease, E. A., Lambert, K., Hickman, D. R., Robinson, O., McCoy, K. T., . . . King, J. K. (2013). Championing person-first language: A call to psychiatric mental health nurses. J Am Psychiatry Nurses Assoc, 19(3), 146-151. http://dx.doi.org/10.1177/1078390313489729

Katims, D. S. (2001). Literacy assessment of students with mental retardation: An exploratory investigation. Education and Training in Mental Retardation and Developmental Disabilities, 36(4), 3633-3372.

Kozulin, A., \& Gindis, B. (2007). Sociocultural theory and education of children with special needs. In H. Daniels, M. Cole, \& J. V. Wertsch (Eds.), The Cambridge Companion to Vygotsky (pp. 332-362). Cambridge University Press. http://dx.doi.org/10.1017/CCOL0521831040.014

LaDuke, C. (1994). Mesa County public library district, final performance report for library services. Retrieved from https://files.eric.ed.gov/fulltext/ED416886.pdf

Learning Disabilities Association of America. (2019). Types of learning disabilities. Retrieved from https://ldaamerica.org/types-of-learning-disabilities/

Lott, E. (2013). Love and theft: Blackface minstrelsy and the American working class. Oxford University Press.

Manning, J., \& Stern, D. M. (2016). Heteronormative bodies, queer futures: toward a theory of interpersonal panopticism. Information, Communication \& Society, 21(2), 208-223. http://dx.doi.org/10.1080/1369118x.2016.1271901 
Mathuews, K. (2016). Moving beyond diversity to social justice. Progressive Librarian (44), 627.

Meyer, A., Rose, D. H., \& Gordon, D. (2014). Universal design for learning: Theory and practice. CAST Professional Publishing.

Moni, K., Jobling, A., \& Baffour, B. (2018). Literacy learning outcomes in a longitudinal study of a postschool literacy education program for young adults with intellectual disabilities. Journal of Policy and Practice in Intellectual Disabilities, 15(2), 155-165. http://dx.doi.org/10.1111/jppi.12247

Mulliken, A., \& Atkins, A. (2009). Academic library services for users with developmental disabilities. The Reference Librarian, 50(3), 276-287. http://dx.doi.org/10.1080/02763870902873461

National Institute for Neurological Disorders and Stroke. (2019). Learning disabilities information page. Retrieved from https:/www.ninds.nih.gov/Disorders/AllDisorders/Learning-Disabilities-Information-Page

National Organization on Disability. (1998). Harris survey of Americans with disabilities. Retrieved from New York: https://eric.ed.gov/?id=ED422692

Next Chapter Book Club (2018). [Email].

Ok, M. W., Rao, K., Bryant, B. R., \& McDougall, D. (2017). Universal design for learning in pre-K to grade 12 classrooms: A systematic review of research. Exceptionality: A Special Education Journal, 25(2), 116-138.

Philips, J. (2019). Anti-gay activists who were, in fact, gay. Retrieved from https://www.ranker.com/list/top-10-anti-gay-activists-caught-being-gay/joanne

Pierce, D. (2001). Language, violence, and queer people. Journal of Gay \& Lesbian Social Services, 13(1-2), 47-62. http://dx.doi.org/10.1300/J041v13n01_05

Port Washington Public Library. (2017). Books for dessert. Retrieved from http://www.pwpl.org/books/books-for-dessert/

Rahman, J. (2012). The N word: Its history and use in the African-American community. Journal of English Linguistics, 40(2), 137-171. https://dx.doi.org/10.1177/0075424211414807

Saint-Laurent, L., Giasson, J., \& Couture, C. (1998). Emergent literacy and intellectual disabilities. Journal of Early Intervention 21(3), 267-281

Satgar, V., \& Williams, M. (2017). Marxism and class. In K. Korgen (Ed.), The Cambridge handbook of sociology: Speciality and interdisciplinary studies (pp. 41-50). Cambridge University Press. http://dx.doi.org/10.1017/9781316418369.006

Slotkin, R. (2000). Regeneration through violence: The mythology of the American frontier, 1600-1860. University of Oklahoma Press.

Standards Committee Subcommittee to Develop Guidelines for Library Services for People with Mental Retardation. (1999). Guidelines for library services for people with mental retardation. Association of Specialized and Cooperative Library Agencies.

Strang, T. M., \& Piasta, S. B. (2016). Socioeconomic differences in code-focused emergent literacy skills. Reading and Writing, 29(7), 1337-1362. http://dx.doi.org/10.1007/s11145016-9639-7

ThinkCollege! (2018). College search. Retrieved November 5, 2019 from https://thinkcollege.net/college-search 
Treanor, B. (2006). The question of Otherness. In Aspect of Alterity: Levinas, Marcel and the Contemporary Debate. Retrieved from https//www.jstor.org/stable/j.ctt13wzvd.04

Vygotsky, L. S. (1978). The interaction between play and development. In M. Cole, V. JohnSteiner, S. Scribner, \& E. Souberman (Eds.), Mind in society: The development of higher psychological processes (pp. 79-91). Harvard University Press.

Wells, S. (1995). Outreach, special needs centers, and mainstreaming services: Options for public library service. In L. L. Walling \& M. Irwin (Eds.), Information services for people with developmental disabilities: The library manager's handbook. Greenwood Press. 